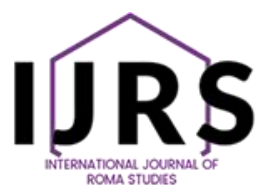

Hipatia Press

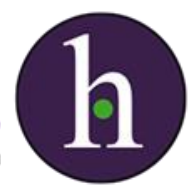

Instructions for authors, subscriptions and further details:

http://ijrs.hipatiapress.com

\title{
Caught in the Crossfire: LGBT+ Traveller Intersectionality in Post-Brexit Britain
}

\section{Regan Eminson ${ }^{1}$}

1) The University of Sussex, United Kingdom

Date of publication: November $15^{\text {th }}, 2021$

Edition period: November 2021 - March 2022

To cite this article: Eminson, R., (2021). Caught in the Crossfire:LGBT+ Traveller Intersectionality in Post-Brexit Britain International Journal of Roma Studies, 3(3), 288-321. doi: 10.17583/ijrs.2020.9123

To link this article: https://doi.org/10.17583/ijrs.9123

\section{PLEASE SCROLL DOWN FOR ARTICLE}

The terms and conditions of use are related to the Open Journal System and to Creative Commons Attribution License (CCAL). 


\section{Caught in the Crossfire: LGBT+ Traveller Intersectionality in Post-Brexit Britain}

Regan Eminson

The University of Sussex

\section{Abstract}

This study aimed to investigate a gap in research regarding the contemporary experiences of individuals who identify as both LGBT+ and Traveller through an intersectional lens in post-Brexit Britain. To fully explore this issue three research questions were formulated; Question 1: What are the experiences of individuals that identify with the LGBT+ community and the Traveller community? Question 2: What are the perceptions of Travellers in the LGBTQ+ community? These questions were explored through both qualitative and quantitative data gathered by two online surveys, which consisted of responses from both LGBT+ Travellers and LGBT+ NonTravellers who were recruited by the method of snowball sampling via social media, the quantitative data was analysed using descriptive statistics and the qualitative data was analysed using thematic coding. The results presented a negative experience for LGBT+ Travellers who felt the need to hide their identity and experienced discrimination in the identified theme of stereotyping in LGBT+ spaces. This research identified a lack of visibility of LGBT+ Traveller identity, in both Traveller and British society which has led to a negative impact upon this intersectional identity, predominantly causing an inability to authentically participate in either community.

Keywords: Intersectionality, LGBT+, Brexit, Identity, Traveller Gypsy 


\section{Atrapados en el Fuego Cruzado: Interseccionalidad el los y las Travellers LGBT+ en el Reino Unido post-Brexit}

Regan Eminson

The University of Sussex

\section{Resumen}

Este estudio tuvo como objetivo investigar una brecha en la investigación con respecto a las experiencias contemporáneas de las personas que se identifican como LGBT + y Viajeros a través de una lente interseccional en la Gran Bretaña posterior al Brexit. Para explorar en profundidad este tema se formularon tres preguntas de investigación; Pregunta 1: ¿Cuáles son las experiencias de las personas que se identifican con la comunidad LGBT + y la comunidad de viajeros? Pregunta 2: ¿Cuáles son las percepciones de los viajeros en la comunidad LGBTQ +? Estas preguntas se exploraron a través de datos cualitativos y cuantitativos recopilados por dos encuestas en línea, que consistieron en respuestas tanto de viajeros LGBT + como de no viajeros LGBT + que fueron reclutados mediante el método de muestreo de bola de nieve a través de las redes sociales, los datos cuantitativos se analizaron utilizando estadísticas descriptivas. y los datos cualitativos se analizaron mediante codificación temática. Los resultados presentaron una experiencia negativa para los viajeros LGBT + que sintieron la necesidad de ocultar su identidad y experimentaron discriminación en el tema identificado de los estereotipos en los espacios LGBT +. Esta investigación identificó una falta de visibilidad de la identidad de los viajeros LGBT + , tanto en la sociedad británica como en la de los viajeros, lo que ha tenido un impacto negativo en esta identidad interseccional, causando predominantemente una incapacidad para participar auténticamente en cualquiera de las comunidades.

Palabras clave: Interseccionalidad, LGBT+, Brexit, Identitad, Travellers 
7 his article will aim to explore, through an intersectional lens, how identity is negotiated for those who consider themselves both 'Traveller' and 'LGBT+'. Traveller identity, particularly Romani identity, is complex and often unique to a specific country or region as stated by Walsh \& Krieg (2007), it is commonly agreed that the Romani diaspora have a shared origin dating back over 1,000 years ago stemming from nomadic groups migrating from the Indian subcontinent. Over the centuries they have developed unique hybridised cultures but with common identifying features such as the 1Romanes language (often hybridised/adapted or an alternative language is used for those who have lost Romanes), a common set of principle values and morals and in some cases traditions subject to region and sub-grouping.

Romani people are most commonplace on the European continent, however the work of Heaslip et al. (2019) clarifies the fact that the UK plays host to a number of Traveller communities (Scottish and Irish Travellers), alongside Romani diaspora (English Gypsies/Romanies/ Romanichal, Scottish Gypsy Travellers, Welsh Gypsies/Kale and European Roma) and other groups; New Age Travellers and Show people.

This complex amalgamation of identities on the British Isles has led to the use of unique terminology for the referencing of these groups, either by

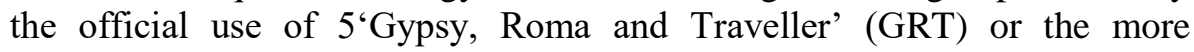
colloquial 'Traveller(s)', to which this study uses both interchangeably for simplification. However, the author acknowledges the uniqueness of the terminology of each group. The term 2'non-Traveller' was chosen and used previously in the work of Harding (2014) to be applied to those in this study who are not members of the Gypsy, Roma or Traveller communities.

Gypsy, Roma and Traveller communities are considered one of the most disadvantaged groups in contemporary Europe, according to Kende et al. (2020), the extent of which is both a socio-cultural issue and an institutional issue. Kende et al. raises the point that anti-Gyspyism/ anti-Traveller discrimination is highly prevalent and considered widely acceptable across Europe. The UK particularly, has seen a surge in hate crime directed towards a number of communities post the Brexit vote of 2016, one of these groups alongside Travellers was highlighted by Channing \& Ward (2017), the LGBT+ community. In a similar aspect to the Traveller community the LGBT+ community in the UK experiences both at an institutional level and a socio-cultural level and in leaving the EU, according to Channing \& Ward, 
an extra layer of defence for the rights of both of these groups previously provided by the European Union has subsequently be removed. Leaving the UK in a unique position politically and socially, distinctly removed from European neighbours.

This study aims to investigate the experiences of LGBT+ Traveller people in light of these fundamental changes to Traveller and British society and politics, also as to what degree these changes may have impacted LGBT+ Traveller's ability to perform or not perform their intersectional identities. This article is constructed in the style of a sociological thesis reflecting upon current and former literature in relevance to Far-Right Populism, Anti-Gypsyism, Homophobia, Traveller Culture and Intersectionality.

\section{Literature Review}

Far-Right parties have gained substantial ground in Europe in recent years, as highlighted by Lazaridis \& Tsagkroni (2016, p. 240), the foundations of which are entrenched in ethno-nationalism, authoritarianism, populism and welfare-nationalism. Parties such as the UK Independence Party (UKIP) and British National Party (BNP) centre ideology around Euroscepticism, antiimmigration and cultural divisions with specific emphasis towards Muslim, LGBT+ and Travelling communities with the aim to alienate these groups as a threat to British identity and as the source of the economic and social discontent in the country.

These parties were propelled by a stagnant economy between 1997-2015 followed by the financial crash of 2008-2015 intermingled with a wave of immigration, as identified by Thom (2015), which led to an explosive resurgence in anti-immigration rhetoric in the media. Interestingly, Thom raises the concept of the displaced halo phenomenon, in which, despite not being directly affected by the issue of immigration, many Britons decided to take the issue upon themselves to oppose the apparent 'threat' of immigration and other 'outsider' groups. Emboldened by the illusion of being a devout British patriot defending the islands from 'invasion', the crescendo of which led to the EU referendum in 2016. Burnett (2017) noted the significant rise in hate crimes attributed to the rise in the right-wing populist victory of the Brexit vote, the Eurosceptic rhetoric of 'taking back control' provided a culture for the growth of particularly Islamophobic and 
anti-immigration attitudes. The visible effects of which saw a rise in hate crimes of $42 \%$ between June 16th and June 30th of 2016 compared to the same period of the previous year.

This wave of right-wing populist attitudes is not something unique to the era of the Brexit referendum \& the Trump election, as highlighted by Jones (2018), right-wing attacks have risen in Europe from 0 incidents in 2012 to 30 in 2017 which can be attributed to the increase in cooperation and coordination between far-right groups globally. Notably, the UK has acutely been affected by this issue, the British government reported the development of such groups promoting white supremacy \& anti-immigration rhetoric has progressed from miniscule, uninfluential groups with older members, to contemporary newfound organisations such as 'National Action' (Secretary of State for the Home Department, 2018). The report summarises; 'The threat from the extreme right wing has evolved in recent years and is growing.' Clearly, there has been a fundamental shift in the prevalence of right-wing attitudes, yet the causation and influence of which is yet to be comprehended.

Hostile attitudes to 'strangers in the midst', as highlighted by Stewart (2012), has been increasing, particularly towards Romani \& LGBT+ people in both continental Europe and the British Isles. Othering has become a fundamental part of European politics, with rhetoric consisting of 'invasion' from other identities, be it sexuality, gender, ethnicity or culture appears to be steadily increasing combined with a strong adherence to ethno-nationalist identities. Several countries: Hungary, Italy, Ireland and the UK have, in the words of Richardson \& Codona (2018), seen a notable rise in anti-GRT rhetoric and acts of violence such as site burning and forcible eviction, this backdrop of anti-GRT sentiment has persisted throughout the entity of pre/post Brexit era. However, particularly Eastern European Roma have been central in the argument for identity politics and populism as the described 'folk-devils' for the purpose of demonisation of an un-empowered people, for the use of peddling a narrative of 'invasion' from a group whose perceived identity is shaped by historical persecution. Interviewees in, Richardson \& Codona's study noted the rise in racism in the UK, providing one such example; 'after Brexit we had people shout at us in the street to go home'.

Far-right populism has had a notable impact on minority communities in the UK, particularly towards immigrant groups and GRT, emphasis towards 
continental Roma is present in a large scope of Far-Right Populist narratives. However, the effects on indigenous GRT groups already present in the UK is unexplored in terms of the post-2016 rise of populist attitudes and has not been addressed directly in the unique post-Brexit political atmosphere of the UK.

\section{Anti-Gypsyism}

Anti-Gypsyism is prejudice towards Gypsy, Roma \& Traveller communities which has been present since the first arrival of Roma into Europe. Historically, the basis of this prejudice began with the Catholic Church, according to Rostas (2017), this was later continually reproduced through the centuries by accompanying policing through nation states, the effects of which previously has led to incidents from general racism, eviction and the refusal to acknowledge identity, to latterly sterilisation and extermination.

In contemporary Britain, Lane et al. (2014) identified the extent of conditions for Travellers, in the report it is stated that the European Court of Human Rights and the United Nations highlighted the difficulty in belonging to the Gypsy, Roma or Traveller community in the UK and compared the circumstances as being analogous to African- Americans in 1950's USA, such is the extent of discrimination on a societal and institutional level. Data from The Traveller Movement (2017) further supports this statement and raises awareness to the experiences of the GRT community, 98\% of participants had experienced discrimination predominantly through hate speech/ crime (81\%) and in educational settings (77\%). Examples include being denied service in pubs/restaurants, threatened with the burning of caravans, physical abuse, refusal of access to healthcare professionals and exclusion in both educational and workplace settings.

As stated by Foster \& Norton (2012), there has been some level of ethnic minority legal protection through parliamentary acts (Equality Act 2010) and the development of such annual awareness events as the GRTHM (Gypsy, Roma \& Traveller History Month), Traveller communities remain one of the most prejudiced groups alongside LGBT+, asylum seekers, refugees and ethnic minorities. Foster \& Norton attributed this level of discrimination to a purposeful lack of positive media representation for Traveller communities.

Anti-Gypsyism evidently is present to a high degree in the cultural fabric of the UK as continual studies have demonstrated into the 21 st century. 
Although recent studies have been conducted into the experiences of GRT individuals, by the Traveller Movement, recent changes in the form of revisited legislation (Parliament. House of Commons, 2020) present a new issue of increased institutional discrimination. The reform in this legislation specifically targets GRT communities and aims to provide greater powers against illegal encampments, such as the forced removal from local authority areas with an extended ban and decreased requirements to enact these powers. As such these recent adaptations to legislation is presumably to impact Traveller communities in a significantly negative manner.

\section{Homophobia}

Homophobia, such as in the case of Anti-Gypsyism, is also facing an upward trend. Bachmann \& Gooch (2017) identified the rise in general hate crime has increased by $48 \%$ with homophobia itself increasing by $70 \%$, interestingly, the correlation between the progression of the far-right populist rise of 2016 is relatively noticeable, between 2013 - 2017 a rise from 9\% to $16 \%$ in terms of the amount of Lesbian, Gay and Bisexual hate crime occurred. What is unclear from this study is whether the data collected could be directly correlated to the event of Brexit or whether this spike between 2013-2017 occurred from another causational factor.

Acceptance of LGBT+ people into British society has progressed in recent decades, with the repeal of the infamous Local Government Act (1988) which introduced Section 28, a controversial piece of legislation which banned the teaching of LGBT+ relationships and issues on a supposed basis of 'moral values', after a wave of panic due to the AIDs epidemic and fear of LGBT+ militant action taking hold during the Thatcherite government. The long-term effects of this act remained, Greenland \& Nunney (2008) highlighted that although the act itself was repealed in 2000 (Scotland)/ 2003 (England and Wales), the impact on education in the UK is still significant and as such assumedly is still presently lacking, the lack of exposure during education could in turn be attributed to the rise in homophobic and transphobic attitudes in the UK.

The report itself seems to contrast with the work of Ahmad \& Bhugra (2010), who highlighted the significant changes in the UK in the past decades, in both a socio-cultural perspective and politico-legal perspective, overall homosexuality in these aspects has improved greatly in the past few 
decades. Anti-homosexual attitudes persist notably in religious communities, it was also stated that research into other cultural experiences at the time were significantly lacking. That statement has changed in recent years and led to the uncovering of data relating to Black \& Minority ethnic groups, according to the work of Magrath et al. (2020), these groups are identified in the UK as holding the most conservative views, regarding sexuality, in comparison to their white British peers. Influence from church congregations appears to be a consistency in the development of these attitudes, as highlighted by Magath et al (in reference to US BME) 'The church in the UK also remains central to many BME communities as a centre for protecting traditional culture and a physical or psychological place for performing identity'.

In a similar instance to anti-Gypsyism current research highlights the perceived increase in homophobic attitudes, the extent of which has been analysed post and during Brexit. However, what is unclear is how different ethnic/ cultural identities have experienced homophobia and whether within these minority groups new pressures from far-right populism have led to a greater increase in conservative attitudes.

\section{Traveller Culture}

Traveller culture is complex and unique in its construct and has endured through conservatism, however changes have occurred in recent years. Particularly amongst Romany populations in the UK, there has been a resurgence in religiosity through born-again Evangelicalism, as stated by Horne (2020) the most influential of which the Chruch ${ }^{1}$ of Light and Life (originally Vie et Lumière). This revival in religious attitudes coincided with the strong sense of protection of the traditional 'Christian morals' and the need for education, the church itself adhered strongly to the ideals of traditional conservative Christian rhetoric combined with an abject wish for the preservation of cultural and ethnic heritage, as seen in other BME communities across the UK. The attractiveness of this revival can be attributed to the unwillingness of Traveller community to assimilate, McGarry (2017, p.30) highlighted the rejection of ${ }^{36}$ Gadje' (non-Romani) culture due to pressure to retain their oppressed identity and authentication in the eyes of other Traveller community members. 
In the study of Derrington (2007), Traveller communities are identified as existing in defiance to assimilation to the dominant culture of the UK. The pull factor of retaining traditional culture has been highlighted as paramount to the GRT community, most notably there is an emphasis on ascertaining milestones earlier, such as financial independence, heteronormative marriage and starting a family.

In addition to this, the retraction from education, especially at an early age, also contributes to the perceived protection of Traveller children from the influence of non-Traveller culture. Most notably in the aspects that nonTraveller communities retain a perceived relaxed or even promotional attitude to promiscuity, drugs and alcohol abuse and other moral issues in the eyes of Traveller people.

One aspect of Traveller cultures which is generally universally present is overt displays of masculinity and a strong emphasis on heteronormativity. Levison \& Sparkes (2003) reported the main aspects identified as central to Romany communities, physical strength, loyalty, business skills, sexual prowess and potency. Displays of masculinity in a physical sense are noted as pertaining to the traditional gender construction and hegemonic ideals, which is one aspect that can translate across ethnic boundaries, however there is an emphasis on 'one-upping' non-Travellers (Gorgers). These aspects of masculinity are identified as central to Romany culture, with high disregard for the exemption of acts/ attitudes outside of these constructions as not-Romanipen (non-Traveller ideals).

Themes of overt masculinity further presents itself in the work and experience of Vanderbeck (2005), in which through Traveller youth support, the researcher, who is from outside of the community, experienced a sense of scrutiny in regard to his own sense of masculinity. Being non-Traveller, he was constantly remarked on by Traveller community members in question of both his masculinity and assumptions regarding his sexual orientation. With comments regarding his academic life as emasculating, volunteering in a nursery setting as 'women's work' and the expectation upon him as an older male by parental figures in the community, to use physical force, aggressive masculinity, for the correction of male youth.

Traveller communities according to the work of Bhopal \& Myers (2016), have seen changes to these long-held traditions, as adapting has become necessary for the survival of the communities in the UK, since the 1960's, these communities traditionally objected to further education participation, 
for fear of the erasure of traditional ways. These communities have had to adapt both socially and culturally in order to survive into the 21 st century, with wide scale changes to British society and the eradication of traditional jobs and other methods of performing Traveller identity, such as seasonal work, the reduction in the ability to live on sites etc.

Traveller culture through the literature clearly retains a strong sense of conservative values, especially regarding sexuality and the performance of masculinity. There is clear evidence of changes in the performance of Traveller identity, adaptation appears to be present in more recent studies for the purpose of economic survival and necessity. What is not clear is the effect these cultural changes have had upon the perception of traditional expectations especially regarding gender performance and the acceptance of non-heteronormative sexualities, and more importantly regarding intersectionality of these aspects of gender and sexuality and Traveller identity.

\section{Intersectionality}

As providing officially recognised proofs of consistent employment is a core As identified by Collins \& Bilge (2020) the key structural domain of power is assembled from social institutions such as housing, education, job markets and health. These domains of power present themselves uniquely for each group, providing some groups with greater power in society than others, impacting upon social relations across societies. Intersectionality specifically analyses where two or more identities intersect and how these impact upon groups, in terms of how identity is constructed and interacts with each other in such examples as; race, class, age, gender and sexuality. In this instance its applicability refers directly to the intersection for LGBT+ Traveller identities.

The work of Fremlova (2017) identified the unique position of continental European LGBT+ Roma due to their subjection as a result of interlocking identities, the amalgamation of which combine both antiGypsyism and non-heteronormativity, both identities appear to be treated consistently in a similar degree across Europe. Fremlova also raised awareness to the increased visibility of LGBT+ Roma at pride events, however inclusion was often tainted by opposition from both non-LGBT+ Roma and other LGBT+, which sparked an interesting aspect of the 
placement of LGBT Roma in society, distinctly in the place between identities, subject to the whims of those dominant or 'authentic' to each group.

The result of which led to a number of participants in the study stating their need to adapt upon reading social situations and mould boundaries of invisibility and visibility in order to 'pass' for the benefit of survival, to not risk exclusion from either community. Fremlova states that the study is not conclusively reflective of all Romani diaspora and differing environments impact upon each sub-grouping, the unique position of the UK, cut off from continental Europe, will most certainly impact upon its communities.

In terms of the intersectionality between sexuality and identity, Baker (2002) highlights the difficulty in harbouring two marginalised identities, the study uncovered the experiences of Romany Gay men, through interviews, and the challenge faced in having to 'pass' in a highly heteronormative culture, neglecting to authentically participate for the purpose of retaining attachment to their family communities and culture. The alternative saw most participants choosing to suppress their ethno-cultural heritage in pursuit of achieving their authentic self. Baker stated the need for changes in visibility of Gay Romanies, in both LGBT+ and Romany communities. It would seem there is a lack of exploration into the development of this aspect of Traveller society post 2002. Baker's study solely reflects upon the Gay Male Romany experience, exploration to other LGBT+ members and other Traveller groups has not been conducted to the same degree in the UK, development into this field could present an opportunity to identify what socio-cultural changes have occurred and the current experience of LGBT+ Travellers in a post-Brexit, post-Marriage Act Britain.

Overall GRT \& LGBT+ intersectionality tends to be centred solely round the Romani experience in both its continental and British forms, with limited scope regarding other groups present in the UK. In terms of intersectionality and identity, the unique placement of UK Traveller communities in a sociocultural and political context is a field in need of exploration due to the separation from continental Romani diaspora and the recent events stemming from 2016 which have led to further isolation for UK Traveller communities.

The sparsity in the current research relating to contemporary intersectional experiences of LGBT+ Travellers. In summary, there is no literature investigating the specific effects of the post Brexit environment 
upon LGBT+ Travellers, which has ultimately affected both Traveller \& LGBT+ communities but has yet to be investigated in an intersectional manner. There is a clear need for the exploration of this identity to comprehend the current experiences and how this identity can or cannot be performed

\section{Methodology}

This researcher wishes to inform the reader that he is a Gay Man of Romany ancestry and therefore has a personal interest in both the communities explored within this study. As white passing and in higher education I acknowledge I have a higher degree of privilege to others in my community, but not to the same extent as my heteronormative white British peers.

The purpose of this empirical research was to gather both quantitative and qualitative primary data for the purpose of measuring the impact of intolerance and populism in British society through the comparative analysis of sentiments towards the following two groups: LGBT+ Travellers \& LGBT+ non-Travellers. As a further means to gain an understanding into the identity construction and experiences of LGBT+ Travellers in contemporary post-Brexit Britain. From the literature review, the following research questions were formulated in order to explore this problem:

What are the experiences of individuals that identify with the LGBT+ community and the Traveller community? What are the perceptions of Travellers in the LGBT+ community?

To answer these questions the paradigm of interpretivism was selected for this research due to the subjectivity of the data in recommendation of Pham et al. (2018), due to the dependency of the data relying upon the dependent variable of experience and perspectives. With the remaining variables comprised of the independent variable of ethnic identity, and the controlled variable of non-heteronormative identities (both gender and/or sexuality subject to the participant). For the benefit of comparison, two sets of data over the period of a month were collected, one for LGBT+ nonTravellers and the other for LGBT+ Travellers so that analysis could be conducted in such areas as; perceptions of British/ GRT society, experiences of discrimination both in ethnic communities and wider society, perspectives of each other and levels of tolerance. 
The online survey aspect of the research aimed for 50 participants from both groups of which there were 9/50 participants for the LGBT+ Traveller Survey and $41 / 50$ for the UK LGBT+ survey. Additionally, online interviews were to be conducted with 10 participants in total, five from the LGBT+ Traveller community and 5 from the UK LGBT+ community, however there were no participants for this aspect.

The method of recruiting participants in this study is centred around the work of Dusek et al. (2015) which emphasises the use of snowball sampling, using social media to reach potential participants from remote or difficult to access groups, in this instance for the purpose of accessing the LGBT+ Traveller community. This is further supported by Baltar \& Brunet (2012), who stated the benefits of removal geographical restrictions normally presented in direct field data collection, in the study of Baltar \& Brunet emailing and messaging was utilised over the platform Facebook, this study used a variable mix of diverse social media platforms (Twitter, Reddit, Instagram, Discord) for the benefit of maximising instances of accessing such a small and remote community as LGBT+ Travellers.

\section{Questionnaire Design}

The tool of use for conducting online surveys was Google forms, as highlighted by Vasantha Raju \& Harinarayana (2016) this tool for data collection was chosen due to the vast number of benefits it has over other survey software. Notably, the ability for the application of mixed methods of both qualitative and quantitative data collection i.e., multiple choice, Likert scales, text boxes etc. The ability to easily distribute access to the survey using the compacted URL option, which is beneficial for use in social media with character restrictions i.e., Twitter, for greater ease in snowball sampling. Also, Google forms has the benefit of automated data analysis and presentation for the enhanced ability to analyse responses accurately, reducing the probability of human error in analysis.

The surveys themselves contain both open and closed questions in order to ascertain both quantitative and qualitative data. The use of open questions to collect qualitative data is supported by the work of Schuman \& Presser (1979), in which there is argument that the provision of the option of open questions allows for the further elaboration of answers distinctly separate from the effects of social desirability, thus allowing for greater in-depth 
responses distinct from the regimented binary of closed questions. Closed questions were also identified as beneficial due to higher response rates by providing clear easy to answer questions which participants could answer in a short amount of time, coupled with open questions for further elaboration. Likert scales are also used within the surveys for the purpose of rating both perspectives and opinions, as suggested by Chyung et al (2017), using 5point scales in these surveys, the neutral central point of which allows participants to offer a truly neutral opinion to not force a participant to agree or disagree but instead provide an honest, unforced answer. Chyung et al, does highlight the instances that the participant lacks knowledge in the field and the suggestion that the midpoint may provide an easy option for those who are uncomfortable with the subject topic.

\section{Interview Method}

Further qualitative data for this survey was intended to be collected via the means of a semi-structured synchronous video interview using the software 'Zoom' due to its wide use in education settings and ability to record interviews for the purpose of transcription, as stated by Janghorban et al. (2014), with other such benefits as the removal of geographical barriers and for the ability for participants to choose their own safe place to conduct the interview. In preparation for this, interview questions were generated, and consent forms created. However, due to an issue regarding recruitment from both groups in this study this method was not conducted.

The possible reason for the lack of participants can be attributed to 'Zoom fatigue', which is a phenomenon unique to the COVID-19 pandemic, identified by Wiederhold (2020), which may decrease the willingness for participation, due to its existing overwhelming presence in day-to-day life for many individuals in work and education settings. Qualitative data to a degree was able to be sourced through the provision of open-ended questions in the online surveys.

\section{Analysis and Ethics}

Regarding data analysis, thematic coding was used for the analysis of qualitative data for the online surveys and was intended to be used for the video interviews. This method of choice is based upon the structure set out 
by Vaughn \& Turner (2016), in which key themes are identified and exclusionary criteria applied. The benefits of this method were highlighted by Nowell et al. (2017), notably the ability to process large quantities of data easily, summarised clearly and for the ability for the researcher to identify popular themes from participant data, a central notion for this study. One disadvantage of this method is the flexibility of the identification of themes, which is subject to the analysis of the researcher. The quantitative data was analysed using descriptive statistics, according to Thompson (2009), the benefits include its use for comparison and highlighting sample characteristics. Due to the sample sizes of this study inferential analysis was not chosen due to its use to generalise populations, which would have not been beneficial for fully comprehending the scope of experiences and perspectives of the participants.

The ethical implications of this research relate to the possible distressing and personal nature of the study, to combat this full anonymisation of the data was guaranteed to the participants and only essential demographic information was collected. Due to the vulnerability and risks posed to the LGBT+ Traveller group especially, additional provision of contact details to professional support services were provided.

\section{Findings and Discussion}

This study aimed to answer the following research questions; 1 . What are the experiences of individuals that identify with the LGBTQ+ community and the Traveller community? 2. What are the perceptions of Travellers in the LGBTQ+ community? The following quantitative and qualitative data was collated from both the LGBT+ Traveller and non-Traveller LGBT+ Google forms online surveys.

\section{Demographic Data}

For a brief overview of participation, a total of 9 of the desired 50 members of the LGBT+ Traveller community participated in the survey and 41 of 50 non-Traveller participants responded to the UK LGBT+ survey. Regarding demographics for the LGBT+ Traveller survey; $90 \%$ of respondents identified with the Romani diaspora with the remaining $10 \%$ identifying themselves as 'Traveller'. The non-Traveller LGBT+ respondents identified 
predominantly as White British (73.2\%) followed by Multiple/Mixed/ More than one ethnic group (14.6\%), White Unspecified (9.8\%) and White Other (2.4\%). The data provided by participants is subjective to their own perceived identity and relies upon the snowball sampling method in order to gather participants from social media platforms.

\section{Research Question 1}

To address the experiences of LGBT+ Traveller participants were initially asked to agree or disagree with the following statement: 'In the past 12 months: I have felt the need to hide my Traveller identity from the LGBTQ+ community'. Over half of the participants agreed with the statement (55.6\%) expressing the need to have hidden their identity from other LGBT+ over the past year, the remaining $44.4 \%$ did not feel they had to hide their identity. A difference of $11.2 \%$ of the participants surveyed expressed the need to hide their identity from their non-Traveller LGBT peers, reflecting the experience of LGBT+ Travellers preferring to hide their identity, as shown in figure 1.

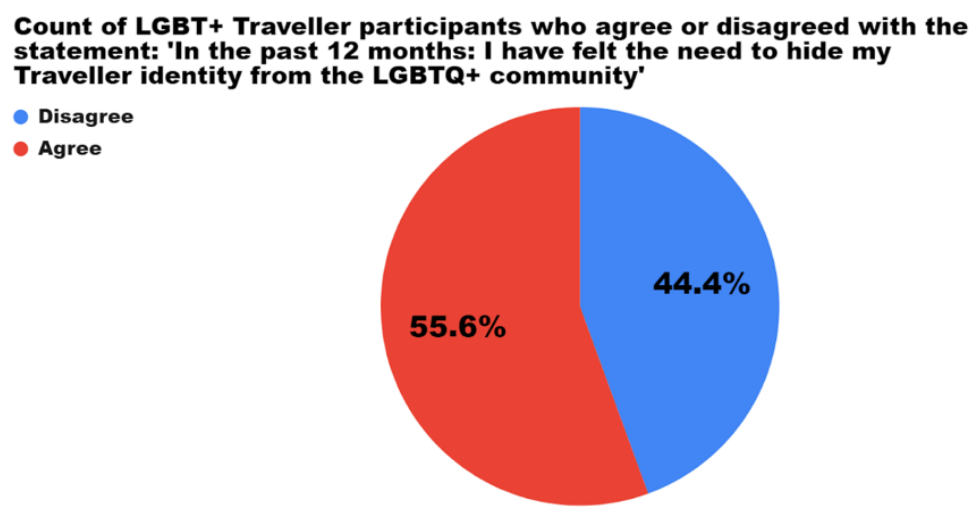

Figure 1. "In the past 12 months: I have felt the need to hide my Traveller identity from the LGBTQ+ community"

To expand upon this, a further statement was presented: 'In the past 12 months: I have experienced discrimination, based on my background, from the LGBTQ+ community'. The results of which are expressed in figure 2, in total $55.6 \%$ of LGBT+ Traveller respondents disagreed that they had experienced discrimination over the past year from the wider LGBT+ 
community, the remaining $44.4 \%$ of participants expressed agreement that they had experienced anti-Traveller discrimination. Therefore an $11.2 \%$ difference is identified in favour of disagreement with the statement favouring the experience that a majority of LGBT+ Traveller participants in this study have not encountered anti-Traveller discrimination from their nonTraveller peers.

\section{Count of LGBT+ Traveller participants who agreed or disagreed with the statement: 'In the past 12 months: I have experienced discrimination, based on my background, from the LGBTQ+ community'}
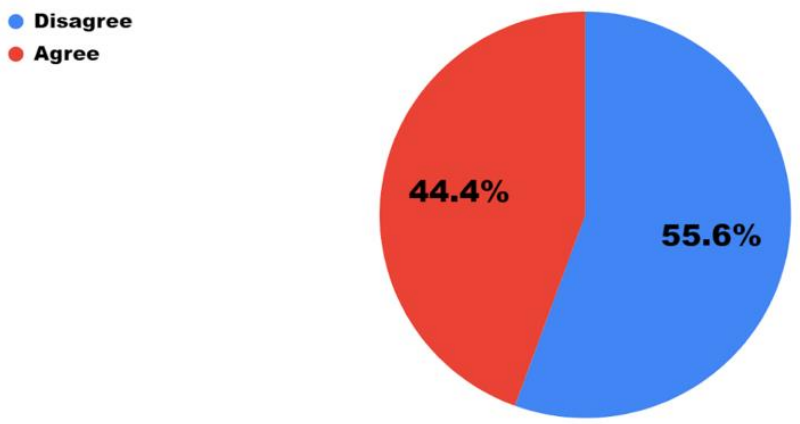

Figure 2. "In the past 12 months: I have experienced discrimination, based on my background, from the LGBTQ+ community"

\section{Count of non-Traveller LGBT+ participants who agreed or disagreed with the statement: 'In the past 12 months: I have experienced discrimination, based on my background (ethnic/ cultural), from the LGBT+ community'}
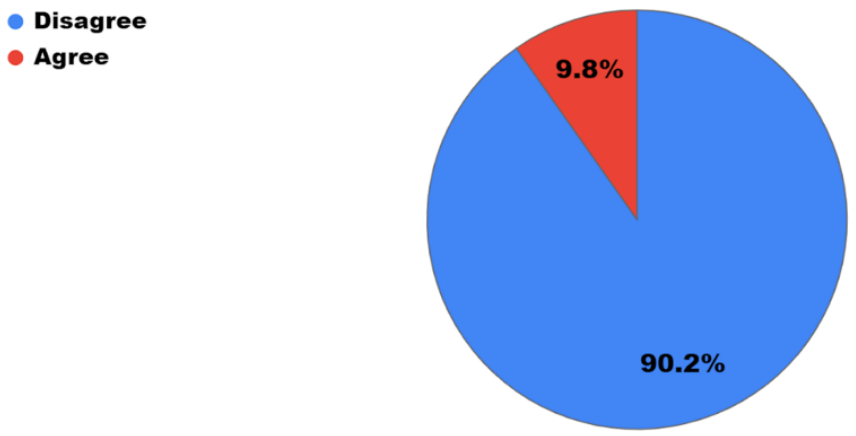

Figure 3. "In the past 12 months: I have experienced discrimination, based on my background (ethnic/ cultural), from the LGBT+ community" 
For the benefit of comparison, a similar statement was asked to the LGBT+ non-Traveller participants: 'In the past 12 months: I have experienced discrimination, based on my background (ethnic/ cultural), from the LGBT+ community'. Of which, $90.2 \%$ of participants disagreed with the statement the remaining $9.8 \%$ of participants agreed with the statement. When contrasted with each other (figure $2 \& 3$ ) there is a clear difference between both sets of participants, $34.6 \%$ more participants agreed that they had experienced discrimination based on their background from the LGBT+ Traveller group than the LGBT+ non-Traveller group.

\section{Stereotyping}

This theme was identified from the Traveller LGBT+ responses to the question 'In the past 12 months: I have experienced discrimination, based on my background, from the LGBTQ+ community', upon offering participants to state 'What type of discrimination did you experience?' 2 responses were collected, with one participant stating. “...I ended up hearing a very long screed against "p*keys" whilst a drag Queen was discussing the possibility of a Gypsy fortune teller theme for her next character ..." (Traveller \& LGBT+ Survey, Respondent 5)

This thematic code and statement chosen from the two responses due to its in-depth description on the use of stereotypical racist perspectives from within the LGBT+ community itself. This response was not anticipated and provides a sample of data reflecting the negative experience of LGBT+ Travellers. Due to the small sample size the validity of this data and its application as a generalisation of the experience of the group as a whole is not conceivable. However, it does provide a glimpse into a previously unexplored field of research in the UK.

In summary, the data suggests a clear preference for LGBT+ Travellers to use of the coping mechanism of hiding their identity, in keeping with the work of Baker (2002) and Fremlova (2017), which appears to reflect in the lessening of Traveller discrimination. However, when contrasted against their non-Traveller peers, LGBT+ Travellers experience more instances of discrimination as anticipated within the literature, this was further supported through the work of Richardson \& Codona (2018) and Glenny (2012), which both stated the prominence of anti-GRT sentiments in contemporary British society, of which also reflected within the qualitative data displaying a level 
of translation into LGBT+ spaces through the medium of the performance of stereotypical racist depictions.

The results indicate the experience of LGBT+ Travellers is largely a negative one in which Traveller identity is hidden in favour of wider LGBT+ acceptance, suggesting an inability to perform this specific intersectional identity. Further research is needed to fully comprehend the general experience of LGBT+ Travellers in the UK, however this research has provided a fundamental knowledge on which to build upon.

\section{Identity Policing}

The presence of control over an identity through 'authentic' participants governing the rules of identity within the community. Traveller communities, as previously stated by Levison \& Sparkes (2003), tend to retain heteronormativity as a central tenet to identity, performed in such ways as heteronormative marriage, family and adherence to traditional gender roles. Identities outside of the heteronormative cis-gendered Traveller as stated by Derrington (2007), appear to be perceived as threatening the existence of Traveller culture through external 'Gadje' influences by presenting the community with non-traditional sexualities and gender identities which are regarded as non-Romanipen. In essence, alternative sexualities and gender identities are considered anti-Traveller and regarded as a mark of the assimilated or " 'Gadjified' Traveller, as highlighted within the literature review. This theme was echoed within the statement of one participant: "Many other Gypsies, especially online, insisting that "Real Gypsies" are never transsexual or gay, that I/we lack romanipen for not being married and having kids, so aren't Romany anymore..." (Traveller \& LGBT+ Survey, Respondent 5)

It would appear from this participant's statement that the perception from Traveller communities highlighted within the literature review can still be regarded as relevant in contemporary Britain. This statement also further illustrated the perceived difficulties for those who harbour nonheteronormative intersectional identities within Traveller communities and the subsequent rejection they face from the wider community, even within virtual spaces.

Due to the sample size, there is questionable doubt over the generalisation of the data and the validity of the response, however the data itself is consistent with previous research and has contributed to further 
comprehension of the issue of sexuality and the difficulties presented with the cohabitation of both Traveller and non-heteronormative identities through an intersectional lens.

\section{Research Question 2}

This second section will present results in relation to the question: 'What are the perceptions of Travellers in the LGBTQ+ community?' Non-Traveller participants were asked a series of questions in relation to the research question, both qualitative and quantitative data was collected. Firstly, questions centred around Likert scales were asked in relation to the participants perceptions of their opinion and knowledge of the GRT community. The first question asked was as follows: 'How would you rate your knowledge of Gypsy, Roma \& Traveller people', on a scale of 1 Limited Knowledge to 5 - Very Knowledgeable.

The results of which are displayed in figure 4 . The average response for this question was a Likert scale rating of 2.49 , with a standard deviation of 0.84 . Indicating an inclination towards a level of 'some knowledge' the second lowest category provided.

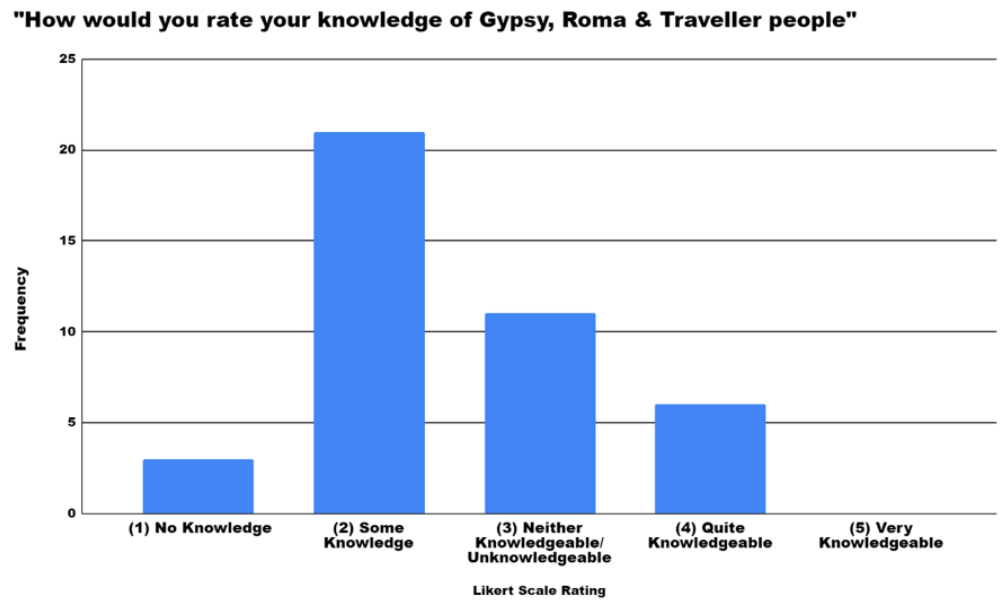

Figure 4. "How would you rate your knowledge of Gypsy, Roma \& Traveller people" 
"How would you rate your opinion of Gypsy, Roma \& Traveller people"

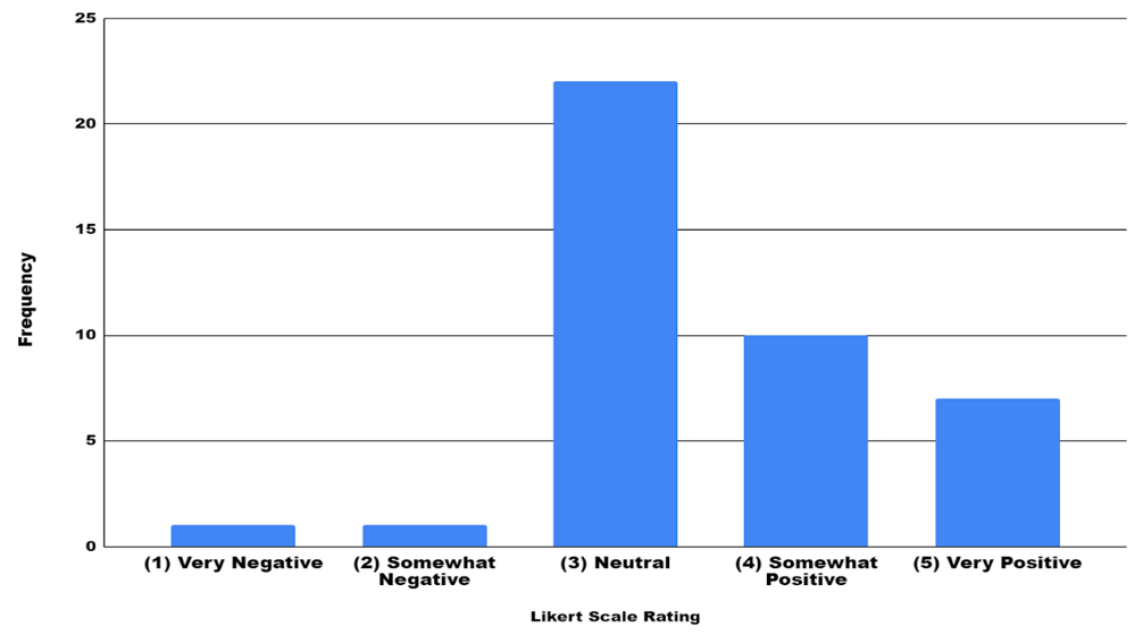

Figure 5. "How would you rate your opinion of Gypsy, Roma \& Traveller people"

Figure 5 displays the results regarding the opinion Likert scale rating of LGBT+ Non-Travellers in relation to LGBT+ Travellers. The Likert scale consisted of 5 points, from 1 - Very Negative to 5 - Very Positive. The average response provided was calculated at 3.51 with a standard deviation of 0.9 , indicating a slightly positive perspective of Travellers within the LGBT+ non-Traveller group but with an overall preference for neutrality by the majority. Interestingly, a similar number of participants selected the 'some knowledge' option (21 participants) in figure 4 as to the 'neutral' option in figure 5 (22 participants), indicating a correlation between a lack of knowledge regarding the community and as such a lack of strong opinion.

LGBT+ non-Traveller participants were then presented with the following question: 'Should Gypsy, Roma \& Traveller people be included in LGBTQ+ spaces (LGBTQ+ nightclubs, bars, Pride events)'. Participants were presented with the options 'Yes', 'No' and 'Prefer not to answer'. Of the 41 respondents $90.2 \%$ chose 'Yes', 7.3\% chose 'Prefer not to answer' and the remaining $2.4 \%$ chose 'No', overall, this data displays a positive response towards inclusion of Traveller LGBT+ in LGBT+ spaces.

The next question asked non-Traveller LGBT+ 'Do you believe Gypsy, Roma \& Traveller discrimination is an important issue in the UK?'. 
Participants were then presented with the same three options as in the previous question. Once again, $90.2 \%$ of respondents chose 'Yes', 7.3\% chose 'Prefer not to answer' and $2.4 \%$ chose 'No', indicating a relationship between those who wish for LGBT+ Travellers to be accepted in LGBT+ spaces and those who believe Traveller discrimination is an important issue in the UK. This degree of wilfulness towards the acceptance of Travellers could be attributed to alternative reasoning to the wish of inclusion, but instead to Gay subculture, Johnson (2008) highlights a degree of fetishism towards groups such as working-class masculine men, termed ${ }^{76}$ chavs' or ${ }^{86}$ scallies'. With Johnson providing examples of nightclubs hosting chav nights and a demand for chav gay sex workers.

This degree of fetishism restricts the sexuality of working-class men by positioning the working-class identity outside of normative gayness. Johnson also discussed how those of higher social classes symbolically power play with the cultural resources and appropriate identities considered beneath them, i.e., fancy dress chav night. In a similar way, Imre (2005) discusses Gypsy romanticism through media representation. such as 'collective passion, "typical" of hot-blooded Gypsies' and 'Gypsy freedom, music, flower-patterned skirts, wild emotions, and horses'. There is a possibility that these two aspects imagined of the hot-blooded Gypsy man, in addition with the categorisation of lower social class masculinity could sprout a form a fetishism within the Gay community which may present itself in a similar way, such as the appropriation of working-class masculinity in a symbolic power play.

\section{Lack of Knowledge}

Participants were provided the opportunity to expand on the question; 'Do you believe Gypsy, Roma \& Traveller discrimination is an important issue in the UK?' through an optional open space, in which participants could provide more detailed responses to this question.

The most populous thematic code, consistent with 5 out of 13 (38.4\%) responses, identified was a 'lack of knowledge', participants who fell within this category either provided evidence of second-hand anecdotal knowledge, stated their own perceived lack of knowledge of discrimination towards the Traveller community or commented upon wider societal ignorance. Each of which is presented in the following participant statements. 
...Britain dislikes Travellers without direct experience

(UK LGBT+ Survey, Respondent 17)

I am unaware / unknowledgeable of traveller issues...

(UK LGBT+ Survey, Respondent 39)

All i know of the people above is from what ive been told by my dad and other queer folks

(UK LGBT+ Survey, Respondent 14)

The conservative nature and unwillingness to intermix with wider British society, as highlighted in the literature via McGarry (2017, p.30), may have severely impacted upon instances of interaction between Traveller and nonTraveller people, as reflected in all three statements, leading to a severe shortage in the ability to acquire knowledge and experience of the community. The code interpreted in this section was anticipated through the previous literature, the perspective of the non-Traveller community appears to be unclear, a lack of knowledge has led to a substantially ill-informed perspective with a primarily neutral stance from the participants in this section.

\section{Minority Blaming}

The code established for this theme of 'minority blaming' was selected due to its prominent feature in the responses, a total of 4 out of $13(30.7 \%)$ of responses referred to negative opinions of Travellers being generated by the actions of a small minority of the community. As presented in the participant statements below:

...I think some, not all, but some members of that community bring on/ encourage some of the views that are perceived about them in society

(UK LGBT+ Survey, Respondent 2)

...its a very few minority that give that whole group a bad name ... (UK LGBT+ Survey, Respondent 12) 
...a lot of traveller communities can be be very disruptive and discriminatory themselves ...

(UK LGBT+ Survey, Respondent 31)

The negative stereotypes of the community remain apparent in the narrative surrounding Travellers with present undertones such as their perceived 'disruptive' nature of the community which 'encourages some of the views' of their 'bad name' in British society.

Additionally, this perspective can be interpreted as stemming from media representation, which itself adheres to the negative historical narrative mentioned in the previous studies. The literature of Morris (2000) highlighted the reinforcement of this narrative present within British media which reaffirmed discriminatory attitudes, which will have influenced the negative perspectives of these participants.

In summary, there is a positive indication towards further inclusion of LGBT+ Travellers into LGBT+ spaces, however what is more prominent from the data is a lack of knowledge regarding Traveller communities by LGBT+ non-Travellers which may contribute to the preference for neutrality in the questions. This response was anticipated through the literature of Chyung et al (2017), who stated the preference for participants to choose a middle ground option when they feel they do not possess a sufficient level of knowledge to decisively choose a response. Further support of the quantitative data was established in the thematic analysis with a lack of knowledge presenting as a prominent theme for participants, this supporting data is further reinforced by the pre-existing literature, therefore there is reasonable grounds for this sample to be consistent with wider British views. Of note, is the contribution of the theme of minority blaming, which has added to the understanding of the perspectives from the LGBT+ nonTraveller community in relation to Traveller communities.

Most notably, the work of Lazaridis \& Tsagkroni (2016, p. 240), especially regarding perceived cultural division of Travellers (them) and non-Travellers (us), appears prominent in the responses to both sets of qualitative data. Especially in relation to the lack of direct knowledge and the application of wider societal views to answer the questions. The theme of minority blaming was identified as coinciding with the prevalence of antiGRT media and its impact upon validating anti-GRT rhetoric on a national level within British society. This section therefore could summarise a need 
for further education on Traveller communities within the UK and the need to address persisting harmful rhetoric.

\section{Conclusion}

In conclusion, this study has explored the contemporary experiences of LGBT+ Travellers through their experiences in Traveller communities and the LGBT+ community, as well as how the Traveller communities themselves are perceived through the lens of the LGBT+ community. This study chose to explore these aspects through two research questions. The first of which was 'What are the experiences of individuals that identify with the LGBTQ+ community and the Traveller community?'. Both the quantitative and qualitative data collected under this research displayed a largely negative experience for those who possess this intersectional identity, with LGBT+ Travellers predominantly choosing to hide their Traveller identities for the benefit of avoiding discrimination from within the wider LGBT+ community. This research particularly resonated with the work of Baker (2000), from which this study was partly based, especially in regard to the ability for LGBT+ Travellers to peacefully cohabitate intersectional identities in British society, along with Vanderbeck (2005) who displayed through experience, the rigidness and expectations regarding heteronormative adherence in a Traveller community. It would appear the most prominent of features correlates to LGBT+ Travellers having to choose one identity over another, as similarly stated in the experience of continental LGBT+ Roma by Fremlova (2017).

The second research question queried 'What are the perceptions of Travellers in the LGBTQ+ community?'. This question was addressed using both qualitative and quantitative data, the research collected for this section indicated a positive perspective on the inclusion of LGBT+ Travellers into shared spaces.

However, these responses were contrasted alongside a substantial declaration of a lack of knowledge about the community and accompanying this a perspective of a perceived negative minority, which appear to be used as a representation of the group. What is clear from the answers to the question is the need for greater education within the LGBT+ community on Traveller communities, distinct from the demonised media representation currently dominating the narrative on perceptions of Travellers identified in 
the work of Morris (2000), which itself translated into the thematic code of 'minority blaming' within this study.

What is positive about this research is the apparent willingness for the LGBT+ community to welcome LGBT+ Travellers, with $90.2 \%$ agreeing to the inclusion of Travellers in LGBT+ spaces and the same $90.2 \%$ further agreeing Traveller discrimination is an important issue.

It was expected that the work of Glenny (2012) \& Richardson \& Codona (2018) would make a greater appearance in this section, negatively influencing the acceptance of Travellers in LGBT+ spaces as expected with the heighted sense of anti-GRT rhetoric defined in each study. However, an accompanying explanation with this, was an identified sense of fetishism and symbolic power play, which may have influenced upon motives behind inclusionary perspectives.

Further exploration is needed within the LGBT+ community as to the acceptance of Traveller members and why this level of acceptance is higher than the wider British populace, this study was limited due to the sample size and method of snowball sampling via social media, which may have restricted access for a number of potential participants. Chiefly, the work of Levison \& Sparkes (2003) and Derrington (2007) still plays relevance to the findings of this study, indicating little to no change in the experiences of LGBT+ Travellers over the span of just under a decade, despite the wider changes to British society as a whole.

There is a degree of limitation to this research, the small sample sizes of the participants involved cannot conclusively display a generalised experience of LGBT+ Travellers in the UK. In hindsight, a larger sample size would have been beneficial to better comprehend experiences. Overall, this study has explored a heavily unresearched field into the experiences of LGBT+ Travellers in the UK and the unique socio-political environment which has been created post the 2016 Brexit referendum.

\section{Notes}

${ }^{\mathrm{i}}$ Romanes - The traditional language of the Romani people, divided into a number of dialects specific to different groups and metagroups of Romani diaspora.-Marushiakova \& Popov (2016)

ii Non-Traveller - Anyone who does not identify as belonging to a Gypsy, Roma or Traveller community- Harding (2014) 
iii Gadje/ Gorger - A term from the Romanes language (spelling subjected to dialect) which refers to anyone who is a non-Traveller - Van Cleemput (2010)

iv Gadjified - This often-derogatory term, from the Romanes language, generally refers to someone who is perceived to be no longer performing traditional cultural/ social practices of Romani identity - Levinson (2007)

${ }^{v}$ GRT - An encompassing term referring to a broad range of Gypsy, Roma \& Traveller (GRT) groups in the UK- Lau \& Ridge (2011)

vi Evangelical 'born-again' mobile church movement catering specifically to Romani diaspora, established in 1952, France. Originally styled 'la Mission Évangélique des Tziganes de France: Vie et Lumière'

vii Chav - Derogatory and demonising term, used towards lower social classes in the UK, associated with antisocial behaviour, violence and criminal activities. Etymologically rooted in the Romanes 'Chavo' meaning Romani child. - Tyler (2006)

viii Scally - Of similar meaning as the word Chav, Scally is a term used also within Gay subculture for the fetishization of the rough working-class hyper-masculinised man. Andersson (2009)

\section{Appendices}

\section{1) Quantitative Raw Data Example}

The screenshot below displays an example of the raw quantitative data collected from the UK LGBT+ online survey. The data was processed and presented using descriptive statistics as outlined in the Methodology. Examples of the data below in presentation and analysis can be seen in Figures $4 \& 5$. 


\begin{tabular}{|c|c|c|c|c|c|}
\hline Bisexual & White British & 3 & 3 & Yes & Yes \\
\hline Lesbian & White British & 4 & 3 & Yes & Prefer not to answer \\
\hline Asexual & White British & 3 & 4 & Yes & Yes \\
\hline Lesbian & White British & 3 & 4 & Yes & Yes \\
\hline Bisexual & White British & 1 & 3 & Prefer not to answer & Yes \\
\hline Bisexual & White British & 3 & 5 & Yes & Yes \\
\hline Gay & White British & 2 & 3 & Yes & Yes \\
\hline Asexual & White & 2 & 5 & Yes & Yes \\
\hline Bisexual & White British & 3 & 4 & Yes & Yes \\
\hline Asexual & Mixed Race & 2 & 2 & Yes & Yes \\
\hline Bisexual & White British & 2 & 4 & Yes & Yes \\
\hline Gay & White British & 2 & 3 & Yes & Yes \\
\hline Pansexual & White British/lrish & 2 & 3 & Yes & Prefer not to answer \\
\hline Queer & White Scottish & 2 & 5 & Yes & Yes \\
\hline Bisexual & White Scottish & 2 & 3 & Yes & Yes \\
\hline Aromantic bisexual & White British & 1 & 3 & Yes & Yes \\
\hline asexual & White British & 2 & 4 & Yes & Yes \\
\hline Bisexual & White British & 2 & 4 & Yes & Yes \\
\hline Pansexual & White British/ltalian & 4 & 3 & Yes & Yes \\
\hline
\end{tabular}

\section{2) Qualitative Coding Example}

This table displays an example of how qualitative data from responses to open ended questions from the Traveller \& LGBTQ+ online survey was thematically coded. The first column displays the raw data, the second column displays themes drawn from the raw data, the third column displays the chosen thematic code assigned to the data, constructed from themes in the second column. The data below can be seen presented and analysed in the 


\begin{tabular}{|l|l|l|}
\hline $\begin{array}{l}\text { As they weren't aware I was Traveller, I ended } \\
\text { up hearing a very long screed against "p*keys" } \\
\text { whilst a drag Queen was discussing the } \\
\text { possibility of a Gypsy fortune teller theme for } \\
\text { her next character. Also hearing a lot of general } \\
\text { use of "Gypsies/pikeys/chavos" as stereotypical } \\
\text { antagonists and as the symbolic opposite of a } \\
\text { queer person. }\end{array}$ & $\begin{array}{l}\text { Discrimination } \\
\text { Appropriation }\end{array}$ & Stereotyping \\
\hline Slurs & \\
\hline Language policing, mostly & $\begin{array}{l}\text { Moderating } \\
\text { language }\end{array}$ & $\begin{array}{l}\text { Language } \\
\text { Policing }\end{array}$ \\
\hline
\end{tabular}

\section{References}

Ahmad, S., \& Bhugra, D. (2010). Homophobia: An updated review of the literature. Sexual and relationship therapy, 25(4), 447-455. https://doi.org/10.1080/14681994.2010.515206

Andersson, J. (2009). East end localism and urban decay: Shoreditch's reemerging gay scene. The London Journal, 34(1), 55-71. https://doi.org/10.1179/174963209X398144

Bachmann, C. L., \& Gooch, B. (2017). LGBT in Britain: Hate crime and discrimination. Stonewall. https://www.stonewall.org.uk/lgbt-britainhate-crime-and-discrimination

Baker D. (2002) The Queer Gypsy: an examination of the dual invisibility of Gay Travellers, [M.A. Thesis, University of Greenwich].Romani Arts. https://t.co/eX6BunRweN

Baltar, F., \& Brunet, I. (2012). Social research 2.0: virtual snowball sampling method using Facebook. Internet research. https://doi.org/10.1108/10662241211199960

Bhopal, K., \& Myers, M. (2016). Marginal groups in marginal times:

Gypsy and Traveller parents and home education in England, UK. British Educational Research Journal, 42(1), 5-20. https://doi.org/10.1002/berj.3198 
Burnett, J. (2017). Racial violence and the Brexit state. Race \& class, 58(4), 85-97. https://doi.org/10.1177/0306396816686283

Channing, I., \& Ward, J. (2017). Homophobia, Brexit and constitutional change. Safer Communities. https://doi.org/10.1108/SC-08-20170032

Chyung, S. Y., Roberts, K., Swanson, I., \& Hankinson, A. (2017). Evidence-based survey design: The use of a midpoint on the Likert scale. Performance Improvement, 56(10), 15-23. http://dx.doi.org/10.1002/pfi.21727

Collins, P. H., \& Bilge, S. (2020). Intersectionality. ( $2^{\text {nd }}$ ed.). John Wiley \& Sons.

Derrington, C. (2007). Fight, flight and playing white: An examination of coping strategies adopted by Gypsy Traveller adolescents in English secondary schools. International Journal of Educational Research, 46 (6), 357-367. https://doi.org/10.1016/j.ijer.2007.06.001

Dusek, G. A., Yurova, Y. V., \& Ruppel, C. P. (2015). Using social media and targeted snowball sampling to survey a hard-to-reach population: A case study. International Journal of Doctoral Studies, 10(1), 279299. m http://ijds.org/Volume10/IJDSv10p279-299Dusek0717.pdf

Equality Act (2010) c 15 Available at; https://www.legislation.gov.uk/ukpga/2010/15/contents (09/02/2021)

Foster, B., \& Norton, P. (2012). Educational equality for Gypsy, Roma and Traveller children and young people in the UK. The Equal Rights Review, 8, 85-112.

https://scholar.google.com/scholar_lookup?hl=en\&volume=8\&public ation_year $=2012$ \&pages $=85$ -

112\&journal=The+Equal + Rights + Review\&author $=$ B. + Foster\&autho $\mathrm{r}=\mathrm{P} .+$ Norton\&title=Educational+equality + for + Gypsy $\% 2 \mathrm{C}+$ Roma $+\mathrm{a}$ nd+Traveller+children+and+young+people+in+the+UK

Fremlova, L. (2020). LGBTIQ Roma and queer intersectionalities: The lived experiences of LGBTIQ Roma. European Journal of Politics and Gender, 3(3), 371-388.

Glenny, M. (2012). The Gypsy" menace": Populism and the new anti-Gypsy politics. M. Stewart (Ed.). London: Hurst. 
Goldston, J. A. (2002). Roma rights, Roma wrongs. Foreign Affairs, 81(2), 146-163.

https://scholar.google.com/scholar?hl=en\&as_sdt=0\%2C5\&q=Goldst on $\% 2 \mathrm{C}+\mathrm{J} .+\mathrm{A} .+\% 282002 \% 29 .+$ Roma + rights $\% 2 \mathrm{C}+$ Roma + wrongs. $+\mathrm{F}$ oreign+Aff. $\% 2 \mathrm{C}+81 \% 2 \mathrm{C}+146 .+\& \mathrm{btnG}=$

Greenland, K., \& Nunney, R. (2008). The repeal of Section 28: it ain't over 'til it's over. Pastoral Care in Education, 26(4), 243-251. https://doi.org/10.1080/02643940802472171

Harding, S. (2014). Social exclusion: Cultural dissonance between Travellers and non-Travellers in British secondary schools. Journal of Student Engagement: Education Matters, 4(1), 25-34. https://ro.uow.edu.au/cgi/viewcontent.cgi?article=1031\&context=jse em

Heaslip, V., Wilson, D., \& Jackson, D. (2019). Are Gypsy Roma Traveller communities indigenous and would identification as such better address their public health needs?. Public health, 176, 43-49. https://doi.org/10.1016/j.puhe.2019.02.020

Hirt, T. (2009). Jakoubek, Marek (ed.): Gypsies and Ethnicity. SociológiaSlovak Sociological Review, (3).

https://scholar.google.com/scholar?q=info:LHs0h5iuM6cJ:scholar.go ogle.com $/ \&$ oi $=$ gsb\&lookup $=0 \& \mathrm{hl}=\mathrm{en}$

https://www.basw.co.uk/system/files/resources/basw_80949-6_0.pdf

Horne, S. (2020). Traveller Theology: A Theological Anthropology Of The Uk's Gypsies And Travellers. Canterbury Christ Church University. https://repository.canterbury.ac.uk/download/b083b448123c01e28eff 462a21d06b65e2d30852eb3f1c8ea897d283978c4f02/4909283/Final $\% 20$ thesis.pdf

Imre, A. (2005). Whiteness in post-socialist Eastern Europe: The time of the Gypsies, the end of race (Vol. 10, p. 261). Albany: State University of New York Press. https://www.researchgate.net/profile/AlfredLopez/publication/266450093_Postcolonial_Whiteness_A_Critical_ Reader_on_Race_and_Empire/links/56ab3c5108aed5a0135aa1cb/Po stcolonial-Whiteness-A-Critical-Reader-on-Race-andEmpire.pdf\#page $=90$ 
Janghorban, R., Roudsari, R. L., \& Taghipour, A. (2014). Skype interviewing: The new generation of online synchronous interview in qualitative research. International journal of qualitative studies on health and well-being, 9(1), 24152.

https://www.ncbi.nlm.nih.gov/pmc/articles/PMC3991833/

Johnson, P. (2008). Rude boys': the homosexual eroticization of class. Sociology, 42(1), 65-82. https://doi.org/10.1177/0038038507084825 Jones, S. G. (2018). Rise of Far-Right Extremism in the United States. Center for Strategic and International Studies (CSIS) https://www.csis.org/analysis/rise-far-right-extremism-united-states

Kende, A., Hadarics, M., Bigazzi, S., Boza, M., Kunst, J. R., Lantos, N. A., ... \& Urbiola, A. (2020). The last acceptable prejudice in Europe? Anti-Gypsyism as the obstacle to Roma inclusion. Group Processes \& Intergroup Relations, 1368430220907701. https://doi.org/10.1177/1368430220907701

Lane, P., Spencer. S.. \& Jones, A. (2014). Gypsy, Traveller and Roma: Experts by Experience Reviewing UK Progress on the European Union Framework for National Roma Integration Strategies. https://arro.anglia.ac.uk/id/eprint/704915

Lau, A. Y. H., \& Ridge, M. (2011). Addressing the impact of social exclusion on mental health in Gypsy, Roma, and Traveller communities. Mental Health and Social Inclusion. https://www.emerald.com/insight/content/doi/10.1108/20428301111 165717/full/html?casa_token=jdrjU5SxDwYAAAAA:dVR4HcGZb8 Ee62qjIS9C9ufiqiPMNK-yYJv4lMC2xHeQ4b3bdLVZN2GKRvP2k9ZgRgrijTLxvT11fDQqtSyd2RfT4zuZtmQ9Piw5jAxfd-jqm1iC0

Lazaridis, G. \& Tsagkroni, V. (2016). Majority Identarian Populism in Britain. In Lazaridis. G, Campani. G, \& Benveniste, A. (Eds.), The Rise of the Far Right in Europe. (pp. 240-241). Palgrave Macmillan. Levinson, M. P. (2007). Literacy in English Gypsy communities: Cultural capital manifested as negative assets. American Educational Research Journal, 44(1), 5-39. https://doi.org/10.3102/0002831206298174 
Levinson, M. P., \& Sparkes, A. C. (2003). Gypsy Masculinities and the School-Home Interface: exploring contradictions and tensions. British Journal of Sociology of Education, 24(5), 587-603. https://doi.org/10.1080/0142569032000127152

Local Government Act 1988 c.9 Available at;

https://www.legislation.gov.uk/ukpga/1988/9/contents (09/02/2021)

Magrath, R., Batten, J., Anderson, E., \& White, A. J. (2020). Examining attitudes towards homosexuality among young, athletic BME men in the UK. Sport in Society, 1-17.

https://doi.org/10.1080/17430437.2020.1844183

Marushiakova, E., \& Popov, V. (2016). Identity and language of the Roma (Gypsies) in Central and Eastern Europe. In The Palgrave handbook of slavic languages, identities and borders (pp. 26-54). Palgrave Macmillan. https://doi.org/10.1007/978-1-137-34839-5_3

McGarry, A. (2017). Romaphobia: The last acceptable form of racism. (pp. 30 - 33) Zed Books Ltd.

Meade, A. W., \& Craig, S. B. (2012). Identifying careless responses in survey data. Psychological methods, 17(3), 437. https://doi.org/10.1037/a0028085

Morris, R. (2000). Gypsies, Travellers and the Media: Press regulation and racism in the UK. Communications Law, 5(6), 213-219.

Nowell, L. S., Norris, J. M., White, D. E., \& Moules, N. J. (2017).

Thematic analysis: Striving to meet the trustworthiness criteria.

International journal of qualitative methods, 16(1)

https://doi.org/10.1177/1609406917733847

Parliament. House of Commons. (2020). Police Powers: unauthorised encampments. (5116). London: The House of Commons Library. https://researchbriefings.files.parliament.uk/documents/SN05116/SN 05116.pdf 
Pham, L. T. M. (2018). Qualitative approach to research a review of advantages and disadvantages of three paradigms: Positivism, interpretivism and critical inquiry. University of Adelaide.

https://www.researchgate.net/profile/Lan-Pham-

3/publication/324486854_A_Review_of_key_paradigms_positivism interpretivism_and_critical_inquiry/links/5acffa880f7e9b18965cd5

2f/A-Review-of-key-paradigms-positivism-interpretivism-andcritical-inquiry.pdf

Richardson, J., \& Codona, J. (2018). Blame and fear: Roma in the UK in a changing Europe. Journal of Poverty and Social Justice, 26(1), 95112. https://doi.org/10.1332/175982717x15127350591914

Rostas, I. (2017). Antigypsyism, education and the media: ways forward. Identities, 24(6), 760-768.

https://doi.org/10.1080/1070289X.2017.1380267

Schuman, H., \& Presser, S. (1979). The open and closed

question. American sociological review, 692712. https://doi.org/10.2307/2094521

Secretary of State for the Home Department (2018) The United Kingdom's Strategy for Countering Terrorism. British Government https://assets.publishing.service.gov.uk/government/uploads/system/ uploads/attachment_data/file/716907/140618_CCS207_CCS0218929 798-1_CONTEST_3.0_WEB.pdf

Stewart, M. (Ed.). (2012) The Gypsy" menace": Populism and the new antiGypsy politics. Hurst \& Company

The Traveller Movement (2017). The last acceptable form of racism?

Thom, B. (2015). Imagined immigration: Did national newspapers influence how A8 and A2 immigration was perceived in the United Kingdom in 2004 and 2014?. https://www.divaportal.org/smash/get/diva2:849393/FULLTEXT01.pdf

Thompson, C. B. (2009). Descriptive data analysis. Air medical journal, 28(2), 56-59. https://doi.org/10.1016/j.amj.2008.12.001

Tyler, I. (2006). Chav scum: The filthy politics of social class in contemporary Britain. M/C Journal, 9(5). https://doi.org/10.5204/mcj.2671 
Vaismoradi, M., Jones, J., Turunen, H., \& Snelgrove, S. (2016). Theme development in qualitative content analysis and thematic analysis. https://www.researchgate.net/publication/290552438_Theme_develo pment_in_qualitative_content_analysis_and_thematic_analysis

Van Cleemput, P. (2010). Social exclusion of Gypsies and Travellers: health impact. Journal of Research in Nursing, 15(4), 315-327. https://doi.org/10.1177/1744987110363235

Vanderbeck, R. M. (2005). Masculinities and fieldwork: Widening the discussion. Gender, Place \& Culture, 12(4), 387-402. https://doi.org/10.1080/09663690500356537

Vasantha Raju, N., \& Harinarayana, N. S. (2016). Online survey tools: A case study of Google Forms. In National Conference on Scientific, Computational \& Information Research Trends in Engineering, GSSS-IETW, Mysore.

https://www.researchgate.net/profile/Narayanaswamy-VasanthaRaju/publication/326831738_Online_survey_tools_A_case_study_of _Google_Forms/links/5c1f9de492851c22a341c79c/Online-surveytools-A-case-study-of-Google-Forms.pdf

Vaughn, P., \& Turner, C. (2016). Decoding via coding: Analyzing qualitative text data through thematic coding and survey methodologies. Journal of Library Administration, 56(1), 41-51. https://doi.org/10.1080/01930826.2015.1105035

Walsh, C., \& Krieg, B. (2007). Roma identity: contrasting constructions. Canadian Ethnic Studies, 39(1-2), 169-186. https://d1wqtxts1 xzle7.cloudfront.net/56121276/39.1-2.walsh-withcover-page-

v2.pdf?Expires $=1631445793 \&$ Signature $=$ fA5IyCAVwln3bdSScUca ZCsnoC9bo4H3J8r7IIfL6bQE2Q9kKLjOO7EhD5HtOzKjU7j1SVtfv wKFfSBkVUCf2Hc2Zh4RcryIwhuWxsRn-

HPVW3czLtZewlQbush2fTgtBK1sE8k 9VF0Ti8Fr1vGPKOeIM6AGtudKS7Ceo3AWEQEjRJbP5mcf8UCjVm6myB79XmubXiq xO5d53dTwi06XQBMZjkIgLy4zfdx5Yo4fnwJ1Ie4LJqEJSp7YznIw tilaim--UZjiaPy3NVFp6-

Oxkxj9cCY8uBv8AOgLZruAWbzKO8AhO8o-

TT3B85JXE6mFKhDCQz8LIPRMdF0zufzA_\&Key-Pair$\mathrm{Id}=$ APKAJLOHF5GGSLRBV4ZA 
Wiederhold, B. K. (2020). Connecting through technology during the coronavirus disease 2019 pandemic: Avoiding "Zoom Fatigue". https://doi.org/10.1089/cyber.2020.29188.bkw

Regan Eminson is a Postgraduate Student at the University of Sussex.

Contact address: re251@sussex.ac.uk 